\title{
PENERAPAN AKUNTANSI LINGKUNGAN DALAM HAL PENGELOLAAN LIMBAH PRODUKSI PADA PERUSAHAAN PENGALENGAN IKAN TUNA PT. SAMUDRA MANDIRI SENTOSA BITUNG
}

\author{
Valencia Matthew Anis ${ }^{1}$, Harijanto Sabijono ${ }^{2}$, Stanley Kho Walandouw ${ }^{3}$ \\ 1,2,3 Jurusan Akuntansi, Fakultas Ekonomi dan Bisnis, Universitas Sam Ratulangi, Jl. Kampus Bahu, Manado \\ 95115, Indonesia
}

E-mail: valenciamatthew.anis@yahoo.com

\begin{abstract}
The purpose of this study is to investigate how the application of environmental accounting in terms of to manage production waste in fish canning companies PT. Samudra Mandiri Sentosa Bitung. This study is qualitative research. This study uses primary data. Primary data were collected by interview. The results of this study are PT. Samudra Mandiri Sentosa has identified, recognized, and measured environmental costs but the company has not made explicit and separate disclosure of environmental cost reports. Stages of treatment of environmental costs are treated as components of production costs, namely direct material costs, direct wage costs, and overhead costs.
\end{abstract}

Keywords: environmental management accounting; environmental accounting; environmental cost

\section{PENDAHULUAN}

Lingkungan merupakan bagian dari kualitas kehidupan dan tidak dapat disangkal bahwa saat ini masalah lingkungan semakin marak menjadi topik diskusi baik di tingkat regional, nasional maupun internasional (Hadi, 2013). Pembangunan sarana infrastruktur yang semakin gencar dilakukan oleh pemerintah serta kegiatan operasional perusahaan membuat lahan hijau semakin berkurang. Kerusakan lingkungan yang terjadi di daerah sekitar kita dianggap merupakan salah satu peran negatif dari keberadaan perusahaan yang hanya cenderung fokus mencari keuntungan tanpa memperhatikan dampak negatifnya terhadap lingkungan sekitar.

Salah satu kegiatan operasional perusahaan adalah kegiatan produksi. Dampak negatif yang dominan ditemukan dalam kegiatan operasional perusahaan adalah polusi suara, limbah produksi, kesenjangan, dan dampak lainya yang dinamakan eksternality (Akbar, 2011). Perusahaan harus menerapkan akuntansi lingkungan dengan tepat agar supaya perusahaan dapat mengelola limbah hasil produksinya tanpa menimbulkan dampak negatif terhadap lingkungan sekitar. Penerapan akuntansi lingkungan bertujuan untuk mengetahui seberapa besar biaya lingkungan yang dikeluarkan dalam pengelolaan limbah dengan menggunakan sistem akuntansi lingkungan sehingga dapat meminimalisir biaya yang dikeluarkan, dapat mengontrol tanggung jawab perusahaan dalam menjaga kelestarian lingkungan perusahaan, serta dapat membuat laporan biaya lingkungan untuk dijadikan pedoman manajemen dalam pengambilan keputusan (Nilasari, 2014).

\section{TINJAUAN PUSTAKA}

Akuntansi manajemen. Menurut Hansen dan Mowen (2016:9), akuntansi manajemen merupakan alat untuk mengidentifikasi, mengumpulkan, mengukur, mengklasifikasikan dan melaporkan informasi yang bermanfaat bagi pengguna internal dalam merencanakan, mengendalikan, dan mengambil keputusan. Akuntansi manajemen adalah proses pengidentifikasian, penghimpunan, penganalisaan, penyusunan, penafsiran, dan 
pengkomunikasian informasi keuangan yang digunakan oleh manajemen untuk merencanakan, mengevaluasi dan mengendalikan kegiatan usaha di dalam sebuah organisasi, serta untuk memastikan penggunaan dan akuntabilitas sumber daya yang tepat (Simamora, 2015:11).

Akuntansi manajemen lingkungan. Menurut Hansen dan Mowen (2016:778), akuntansi manajemen lingkungan merupakan gabungan dari informasi akuntansi keuangan dan akuntansi biaya untuk meningkatkan efisiensi, mengurangi dampak dan risiko lingkungan serta mengurangi biaya lingkungan. Menurut pernyataan International Federation of Accountants IFAC (2005:13), akuntansi manajemen lingkungan merupakan penilaian dan pengungkapan informasi keuangan terkait lingkungan dalam konteks akuntansi dan pelaporan keuangan. Akuntansi lingkungan juga dapat dianalogikan sebagai suatu kerangka kerja pengukuran yang kuantitatif terhadap kegiatan konservasi lingkungan yang dilakukan perusahaan (Lindrianasari, 2007).

Tujuan akuntansi manajemen lingkungan. Tujuan akuntansi manajemen lingkungan sebagai alat manajemen lingkungan. akuntansi lingkungan digunakan untuk menilai keefektifan kegiatan konservasi lingkungan. Data akuntansi lingkungan juga digunakan untuk menentukan biaya fasilitas pengelolaan lingkungan, biaya keseluruhan konservasi lingkungan dan juga investasi yang diperlukan untuk kegiatan pengelolaan lingkungan (Ikhsan, 2008:105).

Manfaat akuntansi manajemen lingkungan bagi industri. Ikhsan (2008:112) mengungkapkan bahwa akuntansi manajemen lingkungan sangat bermanfaat bagi industri, salah satunya adalah kemampuan secara akurat dalam mengidentifikasi, mengestimasi, mengalokasi, mengatur atau mengurangi biaya-biaya khususnya biaya yang berhubungan dengan lingkungan.

Pengertian biaya lingkungan. Biaya lingkungan merupakan biaya yang ditimbulkan akibat kualitas lingkungan yang menurun sebagai akibat dari aktifitas operasi lembaga. Biaya lingkungan harus disajikan secara terpisah dengan laporan keuangan artinya perusahaan harus membuat laporan biaya lingkungan secara khusus untuk memberikan infomasi yang relevan bagi pihak perusahaan maupun pihak luar sebagai pedoman dalam pengambilan keputusan atas dampak lingkungan yang ada (Franciska et al., 2019). Akuntansi lingkungan berkaitan dengan dimasukannya biaya lingkungan environmental cost ke dalam praktek akuntansi perusahaan atau lembaga pemerintah (Handayani, 2010).

Tahapan perlakuan akuntansi biaya lingkungan. Sebelum mengalokasikan pembiayaan untuk pengelolaan dampak lingkungan seperti pengelolaan limbah, pencemaran lingkungan, pencemaran udara, pencemaran suara dan efek sosial lainnya, perusahaan perlu merencanakan tahap pencatatan pembiayaan tersebut. Tahapan ini dilakukan agar dalam pengalokasian anggaran yang telah direncanakan untuk satu periode akuntansi dapat diterapkan dengan efektif dan efisien (Mulyani, 2013). Tahapan akuntansi lingkungan adalah: (1) identifikasi; (2) pengakuan; (3) pengukuran; (4) penyajian; dan (5) pengungkapan.

Penelitian terdahulu. Wanggono (2016) menemukan bahwa rumah potong hewan Surakarta belum menerapkan perlakuan akuntansi biaya lingkungan. Nilasari (2014) menemukan bahwa PG. Djatiroto telah melakukan pengklasifikasian biaya lingkungan dan telah melakukan tahapan perlakuan akuntansi biaya lingkungan. Sela et al. (2019) menemukan bahwa RSUD DR. Sam Ratulangi Tondano belum menyajikan biaya lingkungan dalam laporan secara khusus, namun item-item biaya lingkungan telah tercantunm dalam laporan keuangan perusahaan secara umum. Menurut Sela et al. (2019), kondisi tersebut menunjukkan bahwa rumah sakit telah melakukan pengidentifikasian, pengakuan, pengukuran, penyajian serta pengungkapan biaya lingkungan tetapi informasi atas biaya lingkungan tersebut masih menjadi satu dengan laporan keuangan rumah sakit. Pertiwi (2017) menemukan bahwa pabrik gula Semboro telah melakukan pengklasifikasian biaya 
lingkungan dalam pengelolaan limbah dan telah melakukan perlakuan akuntansi biaya lingkungan.

\section{METODE PENELITIAN}

Jenis metode yang digunakan dalam penelitian ini adalah deskriptif kualitatif. Penelitian ini menggali informasi langsung dari sumbernya, melakukan pemahaman atas informasi yang telah diperoleh, menganalisis hasil penelitian dan menjelaskan temuan yang ada. Penelitian ini dilakukan pada PT. Samudra Mandiri Sentosa Bitung dengan jenis data yang digunakan adalah data kualitatif dan data kuantitatif. Data kualitatif dalam penelitian ini berupa data mengenai jenis limbah dan pengolahannya, sejarah perusahaan, visi dan misi perusahaan, struktur perusahaan serta data mengenai informasi perlakuan akuntansi lingkungan dalam perusahaan. Data kuantitatif dalam penelitian ini berupa data mengenai pengalokasian biaya lingkungan dan juga laporan keuangan tahunan perusahaan. Data penelitian ini diperoleh dan dikumpulkan langsung dari sumber aslinya yaitu dari pegawai PT. Samudra Mandiri Sentosa melalui proses wawancara. Teknik pengumpulan data yang digunakan dalam penelitian ini adalah wawancara dengan pihak PT. Samudra Mandiri Sentosa mengenai gambaran umum perusahaan dan penerapan akuntansi biaya lingkungan.

\section{HASIL ANALISIS DAN PEMBAHASAN}

\subsection{Hasil analisis}

PT. Samudra Mandiri Sentosa bergerak di bidang industri pengalengan Ikan Tuna yang memproduksi bahan baku ikan mentah menjadi barang jadi seperti Ikan Tuna kaleng yang siap dipasarkan. PT. Samudra Mandiri Sentosa terletak di di Jalan Wolter Monginsidi Km.5, Wangurer, Madidir, Kota Bitung, Sulawesi Utara. PT. Samudra Mandiri Sentosa mulai berkiprah dalam perindustrian pengalengan ikan tuna pada tahun 2012 dengan mengakusisi salah satu pabrik pengalengan ikan tuna terbesar di bagian Indonesia Timur dengan kapasitas harian 150 metrik ton. Letak lokasi pabrik pengolahan ikan tidak jauh dengan letak dari perusahaan PT. Samudra Mandiri Sentosa. Lokasi pabrik berbatasan dengan pinggiran laut yang berada di Kota Bitung dan juga terletak di daerah pemukiman warga yang terbilang cukup ramai.

Identifikasi biaya lingkungan PT. Samudra Mandiri Sentosa. Biaya lingkungan selalu berkaitan dengan biaya produk, proses, sistem atau fasilitas penting sebagai dasar pengambilan keputusan manajemen yang baik. PT. Samudra Mandiri Sentosa mengidentifikasi limbah yang dihasilkan menjadi dua bagian yaitu limbah padat dan limbah cair yang akan berdampak negatif bagi lingkungan sekitar. Menurut General Manajer perusahaan bahwa "Biaya yang terkait limbah itu ada tiga macam untuk limbah cair ada biaya bahan penolong, biaya gaji, biaya pengujian kualitas air limbah, limbah padat ada biaya gaji, biaya tuang bongkar limbah, dan biaya penampungan limbah padat ke tempat penampung."

Pengakuan biaya lingkungan PT. Samudra Mandiri Sentosa. Biaya lingkungan diakui oleh perusahaan apabila biaya tersebut sudah digunakan dalam operasional perusahaan dalam mengelola lingkungan dalam hal ini limbah perusahaan. Hal ini sejalan dengan yang diungkapkan Accounting Manager bahwa: "Alokasi biaya pengolahan limbah diambilkan dari rencana anggaran tahunan dan bisa disebut biaya apabila sudah digunakan dalam periode ini". Tabel 1 menunjukkan bahwa pada bulan januari PT. Samudra Mandiri Sentosa sudah mengeluarkan biaya terkait pengolahan limbah yaitu upah operator IPAL dan pembelian bahan penolong, kedua biaya ini akan diakui jika perusahaan sudah menerima manfaat. 


\begin{tabular}{lrr}
\hline \multicolumn{3}{l}{ Tabel 1. Proses pengakuan biaya lingkungan PT. Samudra Mandiri Sentosa } \\
\hline \multicolumn{1}{c}{ Nama rekening } & Anggaran tahun 2019 (Rp) & Realisasi bulan Januari 2019 (Rp) \\
\hline $\begin{array}{l}\text { Biaya Overhead } \\
\text { Bahan Penolong }\end{array}$ & 237.000 .000 & 19.750 .000 \\
$\begin{array}{l}\text { Biaya Upah Langsung } \\
\text { Gaji Pegawai IPAL }\end{array}$ & 480.000 .000 & 40.000 .000 \\
\hline
\end{tabular}

Pengukuran biaya lingkungan PT. Samudra Mandiri Sentosa. Pengukuran biaya lingkungan pada PT. Samudra Mandiri Sentosa menggunakan satuan moneter berdasarkan besaran biaya yang dikeluarkan dan diambil dari realisasi anggaran periode sebelumnya.

Penyajian PT. Samudra Mandiri Sentosa. Penyajian berhubungan dengan bagaimana suatu informasi keuangan akan lampirkan dalam suatu laporan keuangan. Biaya lingkungan yang muncul terkait pengelolaan limbah pada perusahaan PT. Samudra Mandiri Sentosa disajikan bersama-sama dengan biaya-biaya lain yang sejenis ke dalam sub biaya overhead, biaya upah langsung, biaya bahan langsung, dan biaya tak langsung lainnya.

Pengungkapan PT. Samudra Mandiri Sentosa. Berdasarkan hasil penelitian, laporan keuangan perusahaan menggunakan konsep nilai historis, selama ini biaya lingkungan khususnya biaya yang dikeluarkan dalam hal ini biaya pengolahan limbah diperlakukan sebagai biaya overhead, biaya bahan dan upah langsung dan dialokasikan ke produk karena menurut perusahaan pengelolaan limbah yang terjadi berkaitan langsung dengan kegiatan produksi dan memberikan kontribusi yang besar terhadap perusahaan.

\subsection{Pembahasan}

Pengakuan biaya lingkungan. PT. Samudra Mandiri Sentosa menerima dana anggaran untuk periode satu tahun sebagai alokasi anggaran yang masih belum dapat disebut sebagai biaya karena pembiayaan untuk pengelolaan limbah tersebut dilakukan setiap bulan dan pada akhir periode akuntansi akan dijumlahkan untuk dilaporkan pada laporan keuangan. Hal ini sejalan dengan pandangan Anne dalam artikel The Greening Accounting (Winarno, 2008) yang menurut pandangannya bahwa pengalokasian pembiayaan untuk biaya lingkungan dialokasikan pada awal periode dan baru diakui pada saat menerima sejumlah nilai yang telah dikeluarkan.

Pengukuran biaya lingkungan. Pengukuran nilai dan jumlah biaya lingkungan dalam kaitan dengan pengelolaan limbah oleh PT. Samudra Mandiri Sentosa menggunakan satuan moneter sebesar biaya yang dikeluarkan. PT. Samudra Mandiri Sentosa dalam melakukan pencatatan, memasukkan biaya-biaya yang dikeluarkan untuk kegiatan pengelolaan limbah kedalam akun biaya overhead, biaya bahan dan upah langsung serta biaya tak langsung lainnya yang dialokasikan ke produk sehingga besarnya biaya pengelolaan limbah oleh perusahaan dicatat dalam laporan laba rugi.

Penyajian biaya lingkungan. Berdasarkan data yang diperoleh PT. Samudra Mandiri Sentosa menyajikan biaya lingkungan dalam hal ini pengolahan biaya limbah kedalam kelompok biaya produksi didalam sub-sub unit sejenis dalam laporan laba rugi. PT. Samudra Mandiri Sentosa belum menyajikan laporan biaya lingkungan secara khusus dan terpisah namun perusahaan sudah menjalankan kewajibannya dalam pengelolaan lingkungan yaitu dengan cara mengeluarkan biaya-biaya terkait pengelolaan limbah.

Pengungkapan biaya lingkungan. Pengungkapan berkaitan dengan masalah informasi keuangan atau kebijakan akuntansi sebuah perusahaan diungkapkan atau tidak. Sehubungan dengan biaya pengolahan limbah masuk kedalam perhitungan harga pokok produksi, perusahaan sudah mengungkapkan dalam catatan atas laporan keuangan tentang kebijakan akuntansi yang diambil dan diterapkan oleh perusahaan yang berkaitan dengan masalah prosedur pembebanan biaya pengolahan limbah kedalam harga pokok produksi. 


\section{KESIMPULAN DAN SARAN}

\subsection{Kesimpulan}

Perusahaan PT. Samudra Mandiri Sentosa sudah melakukan penerapan akuntansi lingkungan. PT. Samudra Mandiri Sentosa sudah mengeluarkan biaya-biaya lingkungan dalam hal pengelolaan limbah produksi dan juga sudah melakukan aktifitas-akitifitas terkait pengelolaan limbah produksi. Namun PT. Samudra Mandiri Sentosa belum menyajikan laporan biaya lingkungan secara terpisah melainkan biaya-biaya lingkungan tersebut diakui sebagai biaya produksi dan disajikan di laporan laba rugi.

\subsection{Saran}

Berdasarkan kesimpulan diatas, maka saran penelitian ini pada PT. Samudra Mandiri Sentosa adalah:

1. PT. Samudra Mandiri Sentosa sebaiknya menyusun laporan biaya lingkungan dan biaya pengelolaan limbah secara khusus dan terpisah dari laporan keuangan secara umum untuk memberikan informasi terkait pengendalian kualitas lingkungan sebagai usaha peningkatan kualitas lingkungan sekitar.

2. PT. Samudra Mandiri Sentosa diharapkan lebih memperhatikan biaya-biaya lingkungan yang akan dikeluarkan dalam hal pengolahan limbah agar dapat meminimalisir kerusakan lingkungan yang mungkin akan terjadi akibat limbah yang ada.

3. PT. Samudra Mandiri Sentosa diharapkan dapat terus melanjutkan inovasi terkait pengelolaan limbah padat menjadi produk yang memiliki mutu yang tinggi agar dapat meningkatkan pendapatan perusahaan.

\section{DAFTAR PUSTAKA}

Akbar, L.A. (2011). Analisis penerapan akuntansi lingkungan terhadap pengelolaan limbah sebagai salah satu bentuk pertanggung jawaban sosial studi kasus pada PT. Kertas Leces. Skripsi. Universitas Jember. http://repository.unej.ac.id/bitstream/handle/123456789/25366/gdlhub\%20(275)_1.pd f?sequence $=1$

Franciska, R. M., Sondakh, J. J., \& Tirayoh, V. Z. (2019). Analisis penerapan akuntansi lingkungan pada PT. Royal Coconut Airmadidi. Going Concern: Jurnal Riset Akuntansi,14(1), 58-63. https://doi.org/10.32400/gc.14.1.22287.2019

Hadi, S. (2013). Analisis penerapan akuntansi lingkungan pada PT. Istana Cipta Sembada Banyuwangi. Skripsi. Universitas Jember. http://repository.unej.ac.id/handle/123456789/2361

Hansen, D. R., \& Mowen, M. M. (2016). Akuntansi manajerial. Jakarta: Salemba Empat

Handayani, A. R. (2010). Pengaruh environmental performance terhadap environmental disclosure dan economic performance serta environmental disclosure terhadap economic performance studi empiris pada perusahaan manufaktur yang terdaftar di Bursa Efek Indonesia. Skripsi. Universitas Diponegoro Semarang. http://eprints.undip.ac.id/23162/

International Federation of Accountants (IFAC). (2005). International guidance document: environmental management accounting. New York, USA.

Ikhsan, A. (2008). Akuntansi lingkungan dan pengungkapannya. Yogyakarta: Graha Ilmu.

Lindrianasari. (2007). Hubungan antara kinerja lingkungan dan kualitas pengungkapan lingkungan dengan kinerja ekonomi perusahaan di Indonesia. Jurnal Akuntansi dan Auditing Indonesia, 11(2), 159-172. https://journal.uii.ac.id/JAAI/article/view/218 
Mulyani, N. S. (2013). Analisis penerapan akuntansi biaya lingkungan pada Pabrik Gondokurem dan Terpentin (PGT) Garahan-Jember. Skripsi. Universitas Jember. http://repository.unej.ac.id/handle/123456789/2139

Nilasari, F. (2014). Analisis penerapan akuntansi lingkungan terhadap pengelolaan limbah (PG Djatiroto). Skripsi. Universitas Jember. http://repository.unej.ac.id/handle/123456789/63132

Pertiwi, S. A. I. (2017). Analisis penerapan akuntansi lingkungan terhadap pengelolaan limbah studi kasus pada Pabrik Gula Semboro. Skripsi. Universitas Muhammadiyah Jember. http://repository.unmuhjember.ac.id/346/1/Artikel.pdf

Sela, A. Y., Karamoy, H., \& Mawikere, L. M. (2019). Analisis penerapan akuntansi lingkungan pada RSUD DR Sam Ratulangi Tondano. Indonesia Accounting Journal, 1(2), 63-73. https://doi.org/10.32400/iaj.26649

Simamora, H. (2015). Manajemen sumber daya manusia, Edisi 1. Yogyakarta: STIE YKPN.

Wanggono, A. (2016). Analisis perlakuan akuntansi biaya lingkungan. Skripsi. Universitas Sanata Dharma Yogyakarta. https://repository.usd.ac.id/6808/2/122114031_full.pdf

Winarno, W. A. (2008). Corporate social responsibility: Pengungkapan biaya. Jurnal Akuntansi Universitas Jember, 5(2), 72-86. https://www.researchgate.net/publication/301674246_Corporate_Social_Responsibilit y_Pengungkapan_Biaya_Lingkungan 